\title{
Implementation of Telerehabilitation Interventions for the Self-Management of Cardiovascular Disease: Systematic Review
}

Narayan Subedi ${ }^{1}$, MPH; Jonathan C Rawstorn ${ }^{1}$, PhD; Lan Gao ${ }^{2}$, PhD; Harriet Koorts ${ }^{1}$, PhD; Ralph Maddison ${ }^{1}$, PhD

${ }^{1}$ School of Exercise and Nutrition Sciences, Faculty of Health, Deakin University, Melbourne, Australia

${ }^{2}$ School of Health and Social Development, Faculty of Health, Deakin University, Melbourne, Australia

Corresponding Author:

Narayan Subedi, MPH

School of Exercise and Nutrition Sciences

Faculty of Health

Deakin University

221 Burwood Highway

Burwood Victoria

Melbourne, 3125

Australia

Phone: 61404745397

Email: nsubedi@deakin.edu.au

\begin{abstract}
Background: Coronary heart disease (CHD) is a leading cause of disability and deaths worldwide. Secondary prevention, including cardiac rehabilitation (CR), is crucial to improve risk factors and to reduce disease burden and disability. Accessibility barriers contribute to underutilization of traditional center-based CR programs; therefore, alternative delivery models, including cardiac telerehabilitation (ie, delivery via mobile, smartphone, and/or web-based apps), have been tested. Experimental studies have shown cardiac telerehabilitation to be effective and cost-effective, but there is inadequate evidence about how to translate this research into routine clinical practice.
\end{abstract}

Objective: This systematic review aimed to synthesize research evaluating the effectiveness of implementing cardiac telerehabilitation interventions at scale in routine clinical practice, including factors underlying successful implementation processes, and experimental research evaluating implementation-related outcomes.

Methods: MEDLINE, Embase, PsycINFO, and Global Health databases were searched from 1990 through November 9, 2018, for studies evaluating the implementation of telerehabilitation for the self-management of CHD. Reference lists of included studies and relevant systematic reviews were hand searched to identify additional studies. Implementation outcomes of interest included acceptability, appropriateness, adoption, feasibility, fidelity, implementation cost, penetration, and sustainability. A narrative synthesis of results was carried out.

Results: No included studies evaluated the implementation of cardiac telerehabilitation in routine clinical practice. A total of 10 studies of 2250 participants evaluated implementation outcomes, including acceptability $(8 / 10,80 \%)$, appropriateness $(9 / 10$, $90 \%)$, adoption $(6 / 10,60 \%)$, feasibility $(6 / 10,60 \%)$, fidelity $(7 / 10,70 \%)$, and implementation cost $(4 / 10,40 \%)$, predominantly from the participant perspective. Cardiac telerehabilitation interventions had high acceptance among the majority of participants, but technical challenges such as reliable broadband internet connectivity can impact acceptability and feasibility. Many participants considered telerehabilitation to be an appropriate alternative CR delivery model, as it was convenient, flexible, and easy to access. Participants valued interactive intervention components, such as real-time exercise monitoring and feedback as well as individualized support. The penetration and sustainability of cardiac telerehabilitation, as well as the perspectives of CR practitioners and health care organizations, have received little attention in existing cardiac telerehabilitation research.

Conclusions: Experimental trials suggest that participants perceive cardiac telerehabilitation to be an acceptable and appropriate approach to improve the reach and utilization of CR, but pragmatic implementation studies are needed to understand how interventions can be sustainably translated from research into clinical practice. Addressing this gap could help realize the potential impact of telerehabilitation on CR accessibility and participation as well as person-centered, health, and economic outcomes.

Trial Registration: International Prospective Register of Systematic Reviews (PROSPERO) CRD42019124254; https://www.crd.york.ac.uk/prospero/display_record.php?RecordID=124254 
(JMIR Mhealth Uhealth 2020;8(11):e17957) doi: 10.2196/17957

\section{KEYWORDS}

heart diseases; cardiac rehabilitation; telerehabilitation; implementation science; smartphone; systematic review

\section{Introduction}

Cardiovascular diseases (CVDs) are a leading cause of clinical (ie, death and disability), health, and economic burden globally, accounting for approximately $31 \%$ (17.9 million) of total deaths each year [1-3]. Coronary heart disease (CHD), including myocardial infarction (MI) and angina, is the most common and burdensome form of CVD [4,5]. CHD accounts for a high proportion of all CVD deaths and more disability-adjusted life years than diseases such as cancer and diabetes [4-6]. Therefore, secondary prevention interventions that support CVD management are critical to reducing disease burden and health care expenditure.

Cardiac rehabilitation (CR) is an essential component of secondary prevention for CHD that comprises coordinated, multifaceted interventions designed to improve physical, psychological, and social functioning [7-12]. CR includes medical evaluation, exercise prescription, cardiac risk factor modification, education, and counseling [13]. CR is safe, effective [14], and more cost-effective than no CR on overall health service expenditure [15-17]. Systematic reviews have shown that participation in center-based programs (ie, face-to-face delivery) reduces risks of hospital admissions and cardiac mortality, and improves health-related quality of life $[14,18]$.

Despite these benefits, uptake and adherence of center-based CR are suboptimal [19-21]. Reasons for this are multifaceted [22-26], but accessibility-related factors, such as limited availability of programs, transportation, and parking, are prominent [22,24-28]. For these reasons, home-based delivery models have been tested to improve access and participation outside of clinical settings [29].

Home-based CR, which typically includes print resources, home visits, and/or telephone calls, has been shown to be as effective as center-based programs for improving health-related quality of life, CVD risk factors, and mortality [30]. However, few CR services offer home-based options (eg, less than one-quarter in the United Kingdom, United States, and Australia [30,31]). In addition, home-based programs are typically unable to provide the level of supervision, individualized coaching, and feedback from CR professionals that is common in center-based programs. Therefore, alternative delivery models that combine the accessibility of home-based programs with the comprehensive support of center-based CR are needed.

The use of information and communication technologies (ICTs) to connect participants and CR professionals, which is termed cardiac telerehabilitation [32], has been investigated as an alternative. Systematic reviews have demonstrated the effectiveness of cardiac telerehabilitation for improving cardiovascular risk factors and health-related quality of life [33-37]. However, early telerehabilitation interventions were mostly limited to telephone counseling, which limits the types of rehabilitation support that can be provided [38]. Technological innovations including mobile phones, particularly smartphones, and mobile broadband $[39,40]$ have enabled more flexible cardiac telerehabilitation interventions [36,41-43].

Recent studies using cutting-edge technologies, such as smartphones, mobile apps, and the internet, have demonstrated that cardiac telerehabilitation can deliver more comprehensive services [44], including individualized real-time exercise monitoring and coaching, similar to center-based programs [45]. Growing evidence indicates telerehabilitation could substantially broaden the benefits and impact of $\mathrm{CR}$; however, most interventions have only been evaluated in controlled experimental settings (eg, [41-45]). There is little evidence to guide the successful, scalable, sustainable translation of telerehabilitation into real-world settings [46-48]; that is, there is a lack of studies that have tested telerehabilitation interventions when delivered by health care staff in routine clinical practice.

Real-world implementation of an intervention is contextually dependent, influenced by individual (ie, personal characteristics), organizational (ie, hospital or service organization), community (ie, local government), and system-level (ie, government) factors, all of which are difficult to control in experimental designs [49]. Many public health interventions fail to be adopted or are less likely to be scaled and sustained when delivered in real-world settings, and the complexities and challenges involved in real-world implementation and scale-up are partly responsible for this lack of translational success [50]. A greater understanding of factors related to the implementation of interventions in practice settings is imperative for increasing population-level impact [51].

The purpose of this review was to synthesize research evaluating the implementation of cardiac telerehabilitation interventions when delivered in routine clinical practice.

\section{Methods}

\section{Registration}

This review was registered in PROSPERO (International Prospective Register of Systematic Reviews) (CRD42019124254) before screening search results, and was conducted according to the PRISMA (Preferred Reporting Items for Systematic Reviews and Meta-Analyses) statement [52,53].

\section{Information Sources and Search Strategy}

Electronic databases-MEDLINE, Embase, PsycINFO, and Global Health-were searched between January 1990 and November 9, 2018, for studies that combined three concepts: telehealth, CVD, and implementation science. The search strategy was created for MEDLINE and modified for the other databases (see Multimedia Appendix 1). 


\section{Eligibility and Study Selection}

Eligible studies were those that evaluated the implementation of cardiac telerehabilitation in routine clinical practice or assessed implementation outcomes of interest in experimental studies, including randomized and nonrandomized designs, among adults (aged $\geq 18$ years) with CHD (ie, MI, angina, and coronary revascularization).

Cardiac telerehabilitation interventions were defined as those with at least $50 \%$ of the program delivered via ICT, including any mobile phone (ie, feature phone or smartphone), web-based platforms, or wireless devices such as sensors. Implementation in routine clinical practice was defined as interventions delivered as part of existing CR services, without significant ongoing input from a research team.

Experimental studies were included as we anticipated few studies examining real-world implementation, and experimental studies provide the next best available evidence to advance the field; eligibility was not limited to randomized controlled trials (RCTs) to allow the inclusion of translational studies that used alternative study designs. In addition to other criteria, eligible experimental studies were those that assessed constructs defined in a taxonomy of key constructs related to the effective implementation of evidence-based interventions, including acceptability, adoption, appropriateness, feasibility, fidelity, implementation cost, penetration, and sustainability [54]. To acknowledge the importance of multiple stakeholder levels in successful implementation projects $[55,56]$ and to meet the aims of this review, we assessed these constructs at the consumer (ie, participant), individual provider (ie, CR practitioner), and provider (ie, health care organization or institution) levels [54]. Constructs were defined as follows:

1. Acceptability: satisfaction among implementation stakeholders with different aspects of the intervention, such as content, delivery, and complexity. Stakeholders included health care consumers, practitioners, and health care organization operational staff who participated in, delivered, and oversaw the provision of CR services, respectively.

2. Adoption: rates of uptake or utilization of the intervention at the practitioner and/or health care organization level.

3. Appropriateness: program suitability or compatibility at the health care consumer, practitioner, and/or health care organization level.

4. Feasibility: practicability of the intervention for everyday use at the practitioner and/or health care organization level.

5. Fidelity: delivery of the intervention as designed.

6. Implementation cost: assessments of marginal cost, cost-effectiveness, or cost benefit.

7. Penetration: the degree to which the intervention was institutionalized within health care organizations.
8. Sustainability: continued delivery of the intervention beyond the study period, as well as characteristics of the implementation context that did or could influence the continuation of intervention delivery [54].

Feasibility and pilot studies were excluded from this review. To meet the aims of this review, it was important to include only interventions that had already undergone preliminary testing for feasibility and were considered by their respective authors as feasible for testing in the trial or delivery in practice. Conference abstracts, nonhuman studies, non-English-language papers, and grey literature were also excluded. Systematic reviews and study protocols were not eligible for inclusion; however, relevant systematic reviews were searched for eligible studies and cited where appropriate, and results articles were sought for relevant study protocols.

Search results were exported to a reference manager, EndNote X8 (Clarivate), for duplicate removal, then transferred to Rayyan (Qatar Computing Research Institute) for screening [57]. Records were assessed by NS, verified by JR and HK, and underwent full-text review if the title or abstract identified the specified population and intervention components.

\section{Data Extraction}

Data describing eligibility, study design, participant and intervention characteristics, risk of bias, and outcomes of interest were extracted by NS using a standardized electronic form and verified by JR.

\section{Risk-of-Bias Assessment}

Risks of selection, performance, detection, attrition, reporting, and other biases in included experimental studies were assessed using the Cochrane risk-of-bias tool [58]. Risks of bias in nonrandomized cohort studies were assessed using the Joanna Briggs Institute Critical Appraisal Checklist for Cohort Studies [59]. Risks of bias were assessed by NS and verified by JR. When available, risk-of-bias assessments were augmented with study protocols and clinical trial registrations.

\section{Data Synthesis}

A narrative synthesis of the data was carried out in this review.

\section{Results}

\section{Study Selection}

In total, 2044 unique study reports were screened. From these, 21 underwent full-text review; 16 reports describing 10 studies (2250 participants in total) met the eligibility criteria and were included in the narrative synthesis [41-45,60-64]. Study selection is summarized in Figure 1. 
Figure 1. Summary of study selection process using the PRISMA (Preferred Reporting Items for Systematic Reviews and Meta-Analyses) flowchart.

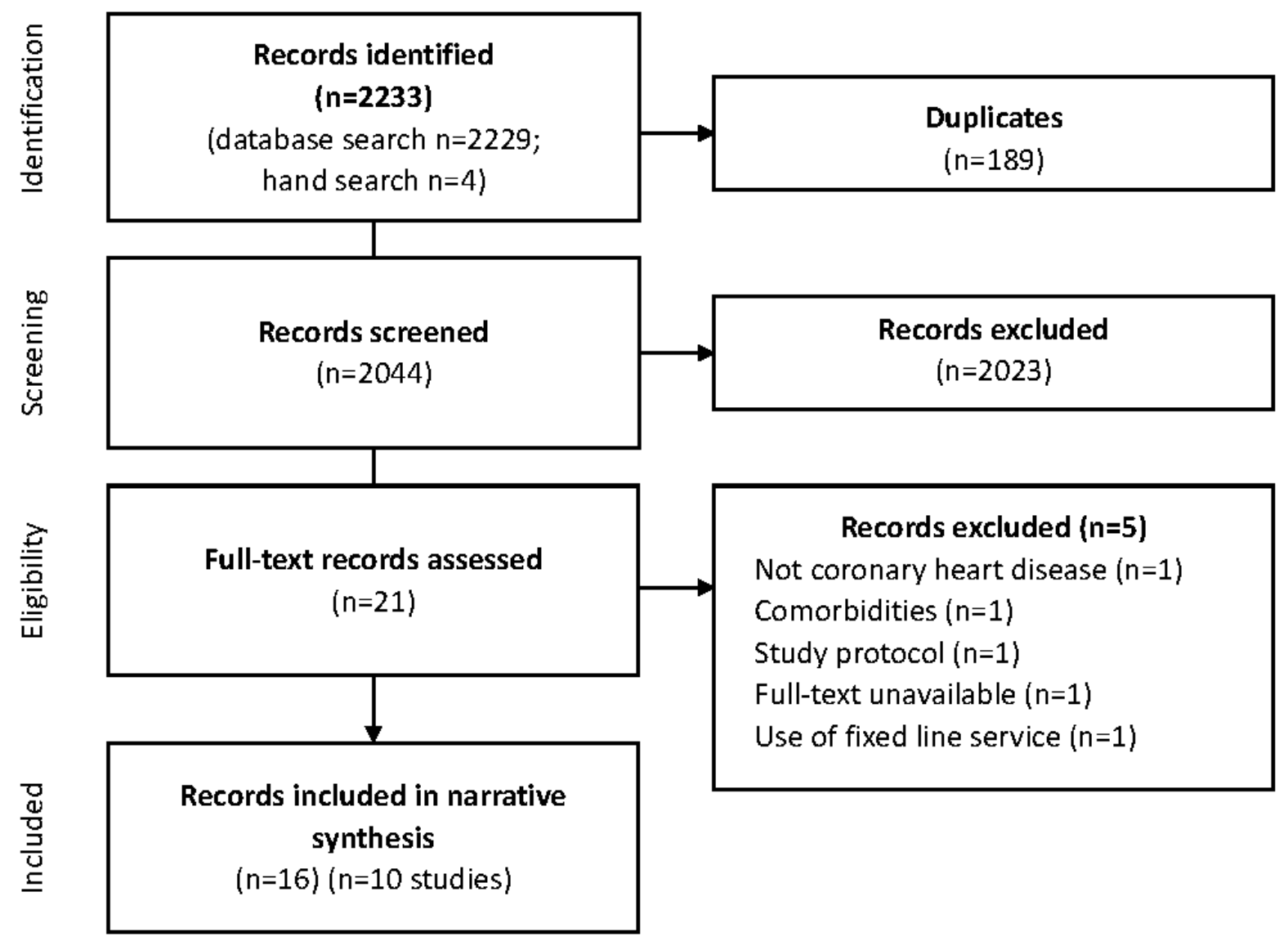

\section{Characteristics of Included Studies}

Included studies were published between 2013 and 2018; studies were conducted in developed countries, including New Zealand [42,43,45], Australia [41,44], Canada [61], the Netherlands [60], Poland [63], and the United States [62]. One multi-country study was carried out in Spain, Germany, and the United Kingdom [64].

No eligible studies were identified that evaluated the effectiveness of the implementation of cardiac telerehabilitation in routine clinical practice. Of the 10 included studies, 9 (90\%) used randomized controlled experimental designs [41-45,60-62,64], while 1 (10\%) used an uncontrolled pre-post intervention design [63].

The mean age of study participants ranged from 55 to 65 years, and most participants were male (72\%-93\%). All studies recruited participants via hospitals or community-based CR centers. Detailed characteristics of the included studies (ie, study design, treatments, and primary and implementation outcomes) are presented in Multimedia Appendix 2.

\section{Cardiac Telerehabilitation Intervention Characteristics}

Out of 10 studies, 3 interventions (30\%) were delivered using a mobile phone, smartphone, or web-based platform alone [41,61,62], while remaining interventions used combinations of web-based content, mobile phones or smartphones, and sensors. The most commonly targeted lifestyle risk factors were physical activity, diet, tobacco smoking, and medication adherence. Intervention duration ranged from 30 days [62] to 24 weeks [41-43] (see Multimedia Appendix 2).

Most interventions $(6 / 10,60 \%)$ comprised a messaging component (eg, SMS or push notifications) [41,43-45,61,62] to educate or motivate participants to improve self-management behaviors. Out of 10 interventions, 7 (70\%) enabled communication between providers and participants via a web-based program, mobile phone or smartphone, and/or telephone $[42,44,45,60,61,63,64]$. Out of 10 interventions, 6 $(60 \%)$ included exercise monitoring [42,44,45,60,63,64], including $2(20 \%)$ that provided live guidance [64] or real-time monitoring and coaching during exercise [45]. Out of 10 studies, $5(50 \%)$ delivered telerehabilitation in combination with usual care (ie, center- or community-based CR) [41-43,45,60], 4 (40\%) delivered cardiac telerehabilitation alone [44,61,62,64], and $1(10 \%)$ delivered a hybrid intervention comprising center-based and telerehabilitation components [63] (see Multimedia Appendix 2).

\section{Risk of Bias in the Included Studies}

The quality of the included studies in the review varied (see Multimedia Appendix 2). Risk of bias was judged to be low in 6 out of $10(60 \%)$ experimental studies [41-43,45,60,61] and high in $3(30 \%)$ studies [44,62,64]. High risk of bias was judged due to incomplete outcome data and lack of blinding of participants and outcomes.

The single nonrandomized study $(1 / 10,10 \%)$ had a high risk of bias due to lack of a control group, not identifying 
confounding factors, and inadequate reporting of follow-up time [63].

\section{Implementation Outcomes}

\section{Overview}

Included studies reported between three and six implementation outcomes. Appropriateness, acceptability, fidelity, adoption and feasibility, were assessed in 9 (90\%), 8 (80\%), 7 (70\%), and 6 $(60 \%)$, of the 10 studies, respectively; cost of intervention was assessed in only $4(40 \%)$ studies, and penetration and sustainability were not assessed. Outcomes were predominantly assessed from a participant perspective, rather than from individual provider (ie, practitioner) or organizational perspectives. Implementation outcome findings are summarized below, with supporting data provided in Table 1 [41-45,60-71]. 
Table 1. Implementation outcomes for telerehabilitation interventions.

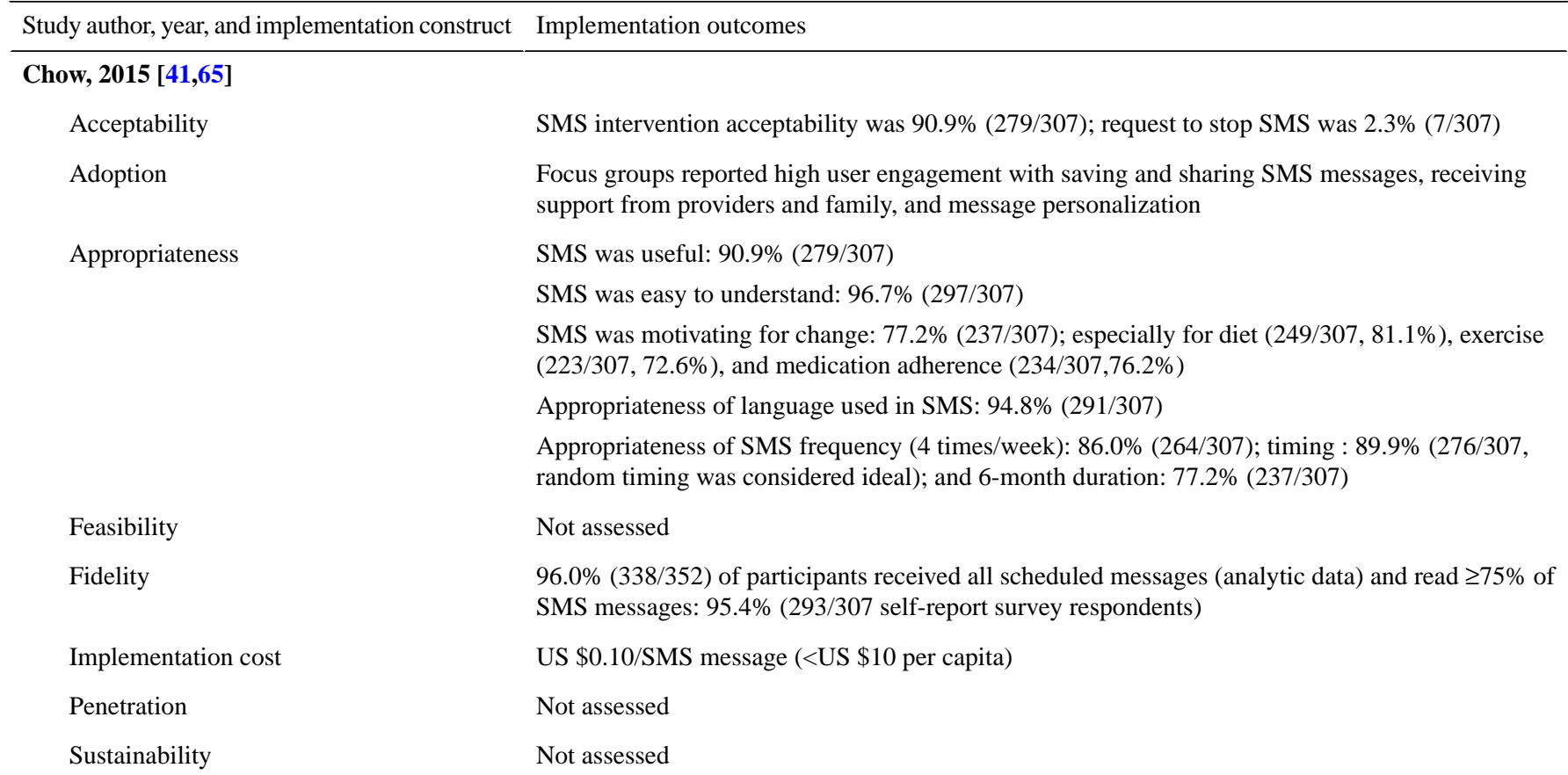

Dale, 2015 [42]

Acceptability

Satisfaction with 24-week program duration was 79\% (48/61) and with number of SMS messages was $84 \%(51 / 61)$

Recommend to other people: $90 \%(55 / 61)$

Adoption

98\% (60/61) of participants initiated the SMS intervention

$\geq 1$ website login: $75 \%$ (46/61); median 3 , range $0-100$

Appropriateness

$90 \%(55 / 61)$ and $43 \%$ (26/61) of participants felt that SMS messages and the website were good cardiac rehabilitation (CR) delivery methods, respectively

Appropriate number of SMS messages: 84\% (51/61)

Intervention useful for learning about $(47 / 61,77 \%)$ and recovering from $(51 / 61,84 \%)$ a heart event and for changing behaviors, such as physical activity $(39 / 61,64 \%)$ and consumption of fruit and vegetables $(37 / 61,61 \%)$, saturated fat $(34 / 61,56 \%)$, and salt $(26 / 61,43 \%)$

Feasibility

Not assessed

Fidelity

Read all SMS messages: 85\% (52/61)

Sent $\geq 1$ SMS step count message: 95\% (58/61); mean of 15 submissions (SD 8.7) over 24 weeks

Implementation cost

Not assessed

Penetration

Not assessed

Sustainability

Kraal, 2013 [60,66]

Acceptability

Adoption

Appropriateness

Not assessed

Feasibility

Fidelity

Implementation cost

Satisfaction was higher for telerehabilitation than for center-based rehabilitation (8.7/10 vs 8.1/10; $P=.02)$

Not assessed

Not assessed

Not assessed

Exercise adherence was similar in telerehabilitation and center-based rehabilitation (mean 22.0, SD 6.8, vs mean 20.6, SD 4.3, sessions)

Similar per-capita cost to deliver telerehabilitation and center-based rehabilitation ( $€ 314$ vs $€ 336$ ) Per-capita costs did not differ between telerehabilitation and center-based rehabilitation for total health care use (mean $€ 2419$, SD 1968, vs mean $€ 2855$, SD 2797; $P=.39$ ) or total work absenteeism (mean €3846, SD 8400, vs mean €6569, SD 8170; $P=.12$ )

Probability of cost-effectiveness was higher for telerehabilitation than for center-based rehabilitation under several assumptions 


\begin{tabular}{|c|c|}
\hline Study author, year, and implementation construct & Implementation outcomes \\
\hline Penetration & Not assessed \\
\hline Sustainability & Not assessed \\
\hline \multicolumn{2}{|l|}{ Lear, $2015[61,67]$} \\
\hline Acceptability & $\begin{array}{l}22 \text { purposively sampled interviews reported satisfaction, acceptability, and confidence in using } \\
\text { virtual CR }\end{array}$ \\
\hline \multirow[t]{3}{*}{ Adoption } & High self-reported engagement and utilization in virtual CR (interview data) \\
\hline & Mean website log-ins was 27 per participant (range 0-140) \\
\hline & Mean engagement in chat sessions with health care providers was 3.6 \\
\hline Appropriateness & Virtual CR perceived to be accessible and effective \\
\hline Feasibility & Virtual CR perceived to be convenient \\
\hline Fidelity & Not assessed \\
\hline Implementation cost & Not assessed \\
\hline Penetration & Not assessed \\
\hline Sustainability & Not assessed \\
\hline \multicolumn{2}{|l|}{ Maddison, 2015 [43,68] } \\
\hline \multirow[t]{3}{*}{ Acceptability } & $\begin{array}{l}\text { SMS and website intervention components were liked by } 57 \%(43 / 75) \text { and } 73 \%(55 / 75) \text { of partici- } \\
\text { pants, respectively }\end{array}$ \\
\hline & Acceptability of 24-week intervention duration: $71 \%$ (53/75) \\
\hline & $\begin{array}{l}\text { Acceptability of message delivery timing: 57\% (43/75); exercise ideas SMS content: 77\% (58/75); } \\
\text { exercise benefits education content: } 79 \% \text { (59/75); and website content: } 47 \% \text { (35/75); } 49 \% \text { (37/75) } \\
\text { did not use the website }\end{array}$ \\
\hline Adoption & Not assessed \\
\hline Appropriateness & $\begin{array}{l}\text { Some (number not reported) participants who were already exercising felt the intervention was un- } \\
\text { necessary or the exercise prescription was not relevant }\end{array}$ \\
\hline \multirow[t]{2}{*}{ Feasibility } & Difficulties using website: $17 \%(13 / 75)$ \\
\hline & Major barriers were lack of high-speed broadband or knowledge about using websites \\
\hline \multirow{2}{*}{ Fidelity } & $93 \%(70 / 75)$ read most SMS messages \\
\hline & $64 \%$ (48/75) used the website (visits per participant: mean 11, SD 16, range 0-82) \\
\hline \multirow[t]{3}{*}{ Implementation cost } & $\begin{array}{l}\text { NZ } \$ 239 \text { per capita (intervention set-up + delivery only; health care utilization and indirect societal } \\
\text { costs excluded) }\end{array}$ \\
\hline & Incremental cost-effectiveness ratio: $\mathrm{NZ} \$ 28,768$ per quality-adjusted life year (QALY) \\
\hline & $\begin{array}{l}\text { Probability of cost-effectiveness: } 72 \% \text { (willingness to pay: NZ \$20,000 per QALY) and } 90 \% \\
\text { (willingness to pay: NZ \$50,000 per QALY) }\end{array}$ \\
\hline Penetration & Not assessed \\
\hline Sustainability & Not assessed \\
\hline \multicolumn{2}{|l|}{ Maddison, 2019 [45,69] } \\
\hline \multirow[t]{2}{*}{ Acceptability } & $\begin{array}{l}87 \%(58 / 67) \text { would choose telerehabilitation instead of center-based rehabilitation if implemented } \\
\text { in clinical practice }\end{array}$ \\
\hline & $\begin{array}{l}\text { Satisfaction with individualized exercise prescription: } 90 \% \text { (60/67); real-time exercise monitoring: } \\
94 \% \text { (63/67); encouragement and social support: } 87 \% \text { (58/67); behavior change messages: } 85 \% \\
\text { (57/67); self-monitoring: } 96 \% \text { (64/67); and goal-setting features: } 69 \% \text { (46/67) }\end{array}$ \\
\hline Adoption & $94 \%(77 / 82)$ of participants initiated telerehabilitation \\
\hline Appropriateness & $\begin{array}{l}97 \%(65 / 67) \text { of patients reported that telerehabilitation is a good approach for delivering exercise } \\
\text { rehabilitation }\end{array}$ \\
\hline \multirow[t]{3}{*}{ Feasibility } & Wearable sensor is easy to use: $99 \%(66 / 67)$; and is comfortable: $97 \%(65 / 67)$ \\
\hline & $\begin{array}{l}\text { Smartphone app is easy to use: } 79 \% \text { (53/67); easy to understand: } 87 \% \text { (58/67); and reliable: } 66 \% \\
(44 / 67)\end{array}$ \\
\hline & Rare technical difficulties, commonly solved with familiarization \\
\hline
\end{tabular}


Study author, year, and implementation construct Implementation outcomes

Fidelity

Implementation cost

Penetration

Sustainability

Park, 2014 [62]

Acceptability

Adoption

Appropriateness

Feasibility

Fidelity

Implementation cost

Penetration

Sustainability

Piotrowicz, $2014[63,70]$

Acceptability

Adoption

Appropriateness

Feasibility

Fidelity

Implementation cost

Penetration

Sustainability

Salvi, $2018[64,71]$

Acceptability

Adoption

Appropriateness
Adherence to prescribed exercise was comparable in telerehabilitation (mean 58.34\%, SD 36.58, range $0-100$ ) and center-based rehabilitation (mean $63.80 \%$, SD 30.59, range 0-100; $P=.31$ )

Lower per-capita program delivery cost for telerehabilitation than for center-based rehabilitation (NZ \$1130 vs NZ \$3466)

No difference in total (ie, program delivery + health care and medication utilization) per-capita cost (NZ \$4920 vs NZ \$9535)

Not assessed

Not assessed

Strong or moderate agreement about intervention satisfaction: $82 \%$ (23/28) for SMS reminders + education; and $88 \%(22 / 25)$ for SMS education alone

Not assessed

Strong or moderate agreement that the interventions were useful for assisting medication adherence: $71 \%(20 / 28)$ for SMS reminders + education; and 48\% (12/25) for SMS education alone

Strong or moderate agreement that interventions were easy to use: $88.6 \%$

Technical difficulties receiving SMS: $7.6 \%$

Not assessed

Not assessed

Not assessed

Not assessed

\section{Not assessed}

Not assessed

Felt safer during exercise with hybrid telerehabilitation than unsupervised: $80.9 \%$

Hybrid telerehabilitation was useful for increasing exercise: $95 \%$; daily physical activity: $80 \%$; and mental health: $71 \%$

Telemonitoring device was very easy or easy to use: $98.3 \%$

No problems self-fitting electrocardiogram (ECG) electrodes: $99.4 \%$

No problems transmitting ECG from home: $84 \%$

Missed $\geq 1$ exercise session due to technical difficulties: $39.3 \%$

Problems communicating with telemonitoring center: $62.8 \%$

Not assessed

Not assessed

Not assessed

Not assessed

Guided exercise telerehabilitation ratings (mean [95\% CI] rating score, max 5) for ease of use: 3.53 (2.94-4.12); interest: 4.42 (4.11-4.74); stimulation: 3.95 (3.49-4.41); and enjoyment: 3.84 (3.464.22)

nb: data represent only $35 \%$ (19/55) of participants randomized to telerehabilitation

$73 \%(40 / 55)$ of participants initiated guided exercise telerehabilitation

Nonadoption was attributed to unavailability of the clinical team

Guided exercise telerehabilitation ratings (mean [95\% CI] rating score, max 5) for usefulness to increase motivation: 4.59 (4.35-4.83); to increase safety: 4.47 (4.13-4.81); and to increase compliance: $4.47(3.93-5.01)$

Overall, guided exercise telerehabilitation was considered appropriate for its purpose 


\begin{tabular}{|c|c|}
\hline Study author, year, and implementation construct & Implementation outcomes \\
\hline \multirow[t]{2}{*}{ Feasibility } & $\begin{array}{l}\text { Exercise sessions affected by technical errors: } 18 \% \text { (ie, poor biosensor signal or connectivity and } \\
\text { poor transmission of data to server) }\end{array}$ \\
\hline & 6 dropouts were attributed to technical challenges \\
\hline Fidelity & $\begin{array}{l}\text { Participants initiated (mean }[95 \% \mathrm{CI}]) 61 \%(76 \%-46 \%) \text { of the prescribed number of exercise sessions } \\
(79 \%[91 \%-67 \%] \text { among } 17 \text { participants who completed the study) and completed } 32 \%(44 \%-20 \%) \\
\text { of the prescribed duration of exercise }(45 \%[59 \%-31 \%] \text { among } 17 \text { participants who completed the } \\
\text { study) }\end{array}$ \\
\hline Implementation cost & Not assessed \\
\hline Penetration & Not assessed \\
\hline Sustainability & Not assessed \\
\hline \multicolumn{2}{|l|}{ Varnfield, 2014 [44] } \\
\hline Acceptability & Not assessed \\
\hline Adoption & $\begin{array}{l}\text { Program uptake (ie, completion of } \geq 1 \text { exercise session) was higher in telerehabilitation than center- } \\
\text { based rehabilitation: } 80 \%(48 / 60) \text { vs } 62 \%(37 / 60) \text {; relative risk }(\mathrm{RR})=1.30,95 \% \text { CI } 1.03-1.64 ; P<.05\end{array}$ \\
\hline Appropriateness & Smartphone-measured step counts increased motivation to reach exercise goals: $84 \%(38 / 45)$ \\
\hline Feasibility & Not assessed \\
\hline Fidelity & $\begin{array}{l}\text { Categorical adherence (ie, completing } 4 / 6 \text { weeks of exercise training) was higher in telerehabilitation } \\
\text { than center-based rehabilitation: } 95 \%(45 / 48) \text { vs } 68 \%(25 / 37) ; \mathrm{RR}=1.40,95 \% \text { CI } 1.13-1.70 ; P<.05\end{array}$ \\
\hline Implementation cost & Not assessed \\
\hline Penetration & Not assessed \\
\hline Sustainability & Not assessed \\
\hline
\end{tabular}

\section{Acceptability}

Out of 10 included studies, 8 (80\%) [41-43,45,60-62,64] reported the acceptability of telerehabilitation interventions from the participant perspective only; none reported acceptability from the individual provider or organization perspectives. Specific outcome measures within the acceptability implementation construct included perceived acceptability, satisfaction, likes and dislikes, interest, stimulation, and enjoyment. Studies reported high rates of acceptance for cardiac telerehabilitation, ranging from $71 \%$ [43] to $99 \%$ of participants [45]. Interventions that facilitated interaction between participants and providers [42,45,60,61,64] and delivered individually tailored content $[43,60]$, in particular, appeared to have high acceptability. However, 4 studies out of $10(40 \%)$ reported lack of interest among some participants $[43,62,64]$. In particular, messaging interventions (eg, SMS and push notifications) were not satisfactory for participants who would prefer face-to-face interaction with rehabilitation professionals [43]. Usability challenges such as insufficient internet connectivity, which fall within the feasibility implementation construct (see Feasibility section below), can also impact negatively on acceptability [42,64].

\section{Adoption}

Out of 10 included studies, 6 (60\%) reported adoption of the intervention from the participant perspective only; none reported adoption from the individual provider or organization perspectives $[41,42,44,45,61,64]$. Specific outcome measures within the adoption implementation construct included initial

uptake and engagement with telerehabilitation interventions. While levels of adoption varied between studies, they were generally high across SMS, website, and smartphone-based interventions. Out of 10 studies, $1(10 \%)$ attributed some lack of adoption to the availability of staff delivering the intervention [64].

\section{Appropriateness}

Out of 10 included studies, 9 (90\%) reported on the appropriateness of cardiac telerehabilitation from the participant perspective; none reported on appropriateness from the individual provider or organization perspectives [41-45,61-64]. Studies included a very broad range of outcome measures within the appropriateness implementation construct, including usefulness; suitability as an alternative CR delivery model; perceptions of safety, reassurance, accessibility, and effectiveness; as well as appropriateness of the intervention content, language, frequency, and duration.

These outcomes were positively appraised by the majority of participants, and cardiac telerehabilitation was perceived as convenient, flexible, safe, instant, private, and user-friendly. Many participants considered messaging (eg, SMS and push notifications) and smartphone apps to be appropriate mechanisms for delivering CR support [41,42,45,61,63]. Comprehensibility and interactivity also appeared to support participants' perceptions of intervention appropriateness. [41-43,45,60,61,63,64]. Participants reported that telerehabilitation interventions were useful for increasing motivation and confidence to exercise, modifying health behaviors such as medication adherence and healthy eating, 
self-monitoring their health condition, and facilitating remote access to individualized exercise support $[41,42,45,61,62,64]$. Small proportions of participants perceived SMS to be either inadequate or unnecessary [41-43,62]. Overall, cardiac telerehabilitation interventions were considered appropriate by most participants [41-45,61-64]; however, significant heterogeneity of intervention designs and outcome measures in the literature we reviewed makes it difficult to identify factors that optimize intervention appropriateness.

\section{Feasibility}

Out of 10 included studies, $6(60 \%)$ reported aspects of feasibility from a participant perspective but not from the individual provider or organization perspectives. Specific outcome measures within the feasibility implementation construct included usability, suitability of interventions for everyday use among participants, system reliability, or technical difficulties experienced by participants [43,45,61-64]. No included studies assessed the feasibility of telerehabilitation delivery from individual provider or organization perspectives.

Large majorities of telerehabilitation participants self-reported that technologies such as SMS, wearable sensors, smartphone apps, and websites were easy to use, convenient, comfortable, and easy to understand [43,45,61-63]. However, some technical challenges were noted. Approximately $20 \%-30 \%$ of participants reported reliability issues during real-time, remotely monitored, exercise rehabilitation, although the authors did not report whether issues were related to the required smartphone app, wearable sensor, or broadband internet connection [45]. Out of 10 studies, $4(40 \%)$ reported a negative impact of unreliable broadband connectivity on user experiences during interventions that included web-based components and/or transmission of data to CR providers, which, at worst, can prevent participants from initiating their telerehabilitation intervention at all [43,62-64].

\section{Fidelity}

Out of 10 included studies, 7 (70\%) reported on the fidelity of intervention receipt and/or completion among participants [41-45,60,64]. Specific outcome measures within the fidelity implementation construct included participant responsiveness or adherence to the intervention, such as receiving all the scheduled SMS messages, program completion, and adherence to prescribed exercise or medication. Large majorities $(\geq 75 \%)$ of participants in SMS interventions self-reported reading all or most messages [41-43]. However, self-reported use of an intervention website was lower [43]. Out of 10 studies, 3 (30\%) demonstrated that adherence to prescribed exercise telerehabilitation sessions was comparable to [45,60], or better than [44], center-based comparators.

Telerehabilitation interventions appeared to be delivered as per study protocols, with the exception of deviations caused by technical challenges (see Feasibility section above); however, only 1 study out of $10(10 \%)$ formally assessed the fidelity of intervention delivery; analytic data indicated all SMS messages were successfully delivered to $96 \%$ of participants [41].

\section{Implementation Cost}

Only 4 of $10(40 \%)$ included studies reported analyses of telerehabilitation intervention cost $[41,43,45,60]$. As interventions appear to have been provided at no cost to participants, these data likely represent cost from an organizational perspective. Specific outcome measures within this implementation construct included intervention delivery cost and cost-effectiveness. Intervention delivery costs varied markedly from US \$10 per capita for an SMS intervention [41] to NZ $\$ 1130$ per capita for a smartphone-based intervention that delivered real-time remote exercise supervision and coaching [45]. Out of 10 studies, $1(10 \%)$ reported that the telerehabilitation intervention delivery cost was comparable to center-based CR [60], while another $(1 / 10,10 \%)$ reported almost $70 \%$ lower delivery costs for telerehabilitation compared with center-based programs [45]. Out of 10 studies, 2 (20\%) that conducted cost-effectiveness analyses reported a $72 \%-90 \%$ probability of cost-effectiveness for an SMS intervention, assuming willingness-to-pay thresholds of NZ \$20,000-\$50,000 per quality-adjusted life year [43], and moderate to high probabilities that telerehabilitation would be more cost-effective than center-based rehabilitation, particularly at low willingness-to-pay thresholds [60]. None of the studies included in this review evaluated how telerehabilitation could be funded as an adjunct to existing CR services (ie, in additional to center-based program delivery costs).

\section{Penetration and Sustainability}

No included studies assessed any outcome measures within the penetration or sustainability implementation constructs.

\section{Discussion}

\section{Principal Findings}

The primary finding of our review is that, despite encouraging evidence for effectiveness [33-37], there is a lack of evidence evaluating the translation of cardiac telerehabilitation interventions from research into routine clinical practice. It is unclear whether this suggests that evidence-based interventions have yet to be implemented in clinical practice, have been implemented without evaluation, or have been implemented and evaluated but not yet published in the scientific literature.

The next best available data comes from a small number of experimental studies that have assessed key constructs related to the effective implementation of evidence-based interventions. Almost all included studies reported factors related to intervention appropriateness, acceptability, and fidelity; however, adoption, fidelity, and cost have received less attention, and intervention penetration and sustainability had yet to be evaluated.

Moreover, while consumers (ie, CR participants), individual providers (ie, CR practitioners), and organizations (ie, health care services) all play critical roles in achieving successful implementation outcomes [54,72], the cardiac telerehabilitation literature we reviewed has focused only on the consumer perspective. This may reflect the lack of research conducted in routine clinical practice, as individual and organizational providers may have little involvement in the delivery or 
management of telerehabilitation interventions during experimental trials.

Cardiac telerehabilitation was generally well accepted among the majority of participants, even across a broad range of different interventions. While the small number of studies in our review makes it difficult to determine which interventions may be most acceptable to participants, intervention features that enable participants to communicate with practitioners and receive tailored or individualized support appear to promote high rates of acceptance. Unfortunately, acceptability has not yet been evaluated from a delivery perspective, so the perceptions of rehabilitation providers (ie, individual practitioners and organizations) remain unknown. Cardiac telerehabilitation was considered an appropriate delivery model by many participants, particularly those who value convenient, flexible, and accessible intervention support. Moreover, many participants reported that cardiac telerehabilitation was useful for improving their self-management of lifestyle behaviors and CVD risk factors. At the participant level, acceptability and appropriateness also appear to be moderated by intervention feasibility. Interventions that were simple to access, easy to use, reliable, and delivered through ubiquitous mobile, smartphone, and/or web technologies appeared to have higher acceptability and appropriateness.

As our review findings are drawn from experimental studies, it is unclear if they would generalize to the delivery of cardiac telerehabilitation in routine clinical practice. In particular, the predominance of randomized treatment allocation in included studies differs markedly from a recommendation that $\mathrm{CR}$ participants should be offered a choice of alternative CR delivery models that best fit their needs and preferences [73]. Studies that include preference-based treatment allocation are needed to mimic this key element of routine clinical practice or, better yet, evaluation studies should be conducted in parallel with the translation of cardiac telerehabilitation into routine clinical practice. The single non-RCT included in the review reported high acceptance and usability among participants who preferred telerehabilitation [63].

Reporting of participant-level feasibility was mixed, which may reflect the difficulty of documenting both the incidence and impact of usability and technical challenges. However, collectively the evidence suggests telerehabilitation is feasible for most participants. Feasibility among individual and organizational providers is also critical for successful implementation [74,75] but, similar to other implementation constructs, was not evaluated in the included studies.

Fidelity is one of the important implementation outcomes, as it contributes to intervention quality [54]. While 7 of 10 (70\%) included studies reported high intervention uptake, some outcome measures of adherence may be confounded by self-reporting bias. Reassuringly, 3 (30\%) studies indicate that adherence to cardiac telerehabilitation can be at least as high as center-based programs $[44,45,60]$. A key gap in the literature we reviewed is the lack of information about the fidelity of intervention delivery from the perspectives of individual and organizational providers, which is critical to understand when implementing new interventions to maintain intervention quality
[76]. This may reflect known challenges in measuring implementation constructs and a lack of available validated tools [54]; however, we note that the delivery fidelity of interventions that require little, if any, provider input (eg, SMS) may be sufficiently assessed via software analytics.

There was little specific evidence that intervention delivery deviated from study protocols in the included studies, but it is unclear whether this indicates high fidelity intervention delivery or a lack of documentation to support such a conclusion. While future translational research could comprehensively evaluate the fidelity of intervention delivery, comparisons with preceding experimental research may be confounded by assumptions about equivalence between experimental and translational research contexts.

Intervention cost is a key contributor to low uptake of interventions by health care providers [77], and comparison of costs and cost-effectiveness is crucial for making evidence-based decisions about implementing and scaling new interventions [76]. Relatively few included studies reported economic analyses, and telerehabilitation costs varied markedly across different intervention designs. Our review indicates that telerehabilitation can reduce $\mathrm{CR}$ delivery costs and be cost-effective, but it is unclear if cost-effectiveness varies between different types of interventions. For example, interventions that require significant practitioner input, such as real-time remote exercise monitoring and coaching [45], may be substantially cheaper to deliver than center-based programs but more expensive than semiautomated interventions, such as SMS [43]. Whether or not an intervention represents good value depends on health effects and costs, as well as intervention and health care objectives. Therefore, examining the cost and health effects of telerehabilitation interventions in routine clinical practice is essential to provide more valuable information for implementation and scale-up.

The remaining implementation constructs of interest in this review-penetration and sustainability-were not assessed in any included studies. This was not surprising, as penetration and sustainability are more relevant to the mid- and later stages of implementation [54]. Short-duration experimental trials limit penetration to those who are willing to volunteer for research and preclude assessment of longer-term intervention sustainability. As a result, we lack valuable information on factors that could influence the sustainability of the interventions and how this might impact potential scale-up.

\section{Opportunities for Future Research}

Evidence suggests the spread, scale-up, and sustainability of health care innovations are influenced by a broad range of factors related to the people who receive (ie, participants) and deliver (ie, health care practitioners and providers) the innovations as well as by numerous organizational and societal factors $[55,56,74]$. The experimental studies in our review focused on a relatively narrow range of outcomes, omitted the individual and organizational provider stakeholder levels, and could not replicate the complexity of implementation in routine clinical practice. Robust experimental evaluation of effectiveness and safety is critical before real-world implementation [78]. However, it is now critical to evaluate the implementation of 
proven interventions in routine clinical practice, preferably as a complementary adjunct to existing center-based programs, to incorporate the critical element of consumer choice that we and others have advocated [45,73]. Such studies should target all key implementation constructs across all relevant stakeholder levels, be embedded fully in routine clinical practice, and be evaluated for a sufficient duration to enable comprehensive assessment of all factors that contribute to successful, scalable, and sustainable implementation [74].

While it was beyond the scope of this review, an understanding of the relative importance of different factors on the implementation of telerehabilitation interventions in clinical practice is also needed. Although effective implementation is understood to be an interactive combination of factors [74], our review highlights the variability in the assessment and reporting of implementation constructs. It is unknown if this variability was due to, for example, researchers' perceived importance of specific factors when selecting the study outcomes, evidence for the differential impact of implementation factors on outcomes, or the feasibility of evaluating multiple factors within a trial design. Improving the translation of interventions into routine clinical practice requires a greater understanding of the roles of implementation factors and consistent measurement of their impact. Research that explores the relative importance of such factors would greatly advance our ability to effectively scale interventions.

\section{Strengths and Limitations}

A major strength of this review was the use of a robust systematic review methodology to understand a novel research area. Secondly, while broad variability of intervention designs across a small number of studies makes it difficult to determine how to optimize telerehabilitation for translation into clinical practice, it provides a broad overview of potential issues that could be associated with implementation and scale-up.
The findings of our review are primarily limited by a lack of studies that have evaluated cardiac telerehabilitation interventions when implemented in routine clinical practice. The assessment of implementation-related outcomes during controlled experimental studies provides some insight, but marked differences within the context of real-world rehabilitation service delivery limit their generalizability. Additionally, while promising early evidence for effectiveness, safety, acceptability, and cost of cardiac telerehabilitation interventions [33-37] suggest they could play an important role in increasing overall participation in $\mathrm{CR}$, it remains unclear whether positive trial outcomes will be retained following translation into clinical practice [76]. Our review includes a small number of studies with relatively small sample sizes and homogenous cohorts. This may limit generalizability to population subgroups who are typically underserved by $\mathrm{CR}$, including older adults, women, people living in regional or rural areas, and people with diverse non-English-speaking cultural backgrounds [41-45,60,64]. Finally, there was a lack of studies from developing countries where telerehabilitation could have an even greater impact due to a low provision of traditional center-based CR [79-81].

\section{Conclusions}

Cardiac telerehabilitation interventions appear to be acceptable and appropriate for many participants in experimental trials and may be a cost-effective way to increase the reach and utilization of CR. However, explicit implementation studies are urgently needed to inform best-practice translation into routine clinical practice. When possible, such studies should implement telerehabilitation in parallel with existing center-based programs so consumers can autonomously match program delivery models to their individual needs and preferences.

\section{Acknowledgments}

We would like to thank Ms Rachel West, Liaison Librarian, at Melbourne Burwood Campus, Deakin University, for her guidance in finalizing the search strategy. NS received a Deakin University Postgraduate Research Scholarship for his PhD from the university.

\section{Authors' Contributions}

NS, JR, and RM designed the study. NS conducted the search; removed the duplicates; screened the titles, abstracts, and full text of the studies; and drafted the systematic review manuscript. JR and HK contributed to verifying screening, and JR contributed to the full-text review and drafting the manuscript. All coauthors-JR, LG, HK, and RM-contributed to the critical revision of the manuscript and approved the final manuscript.

\section{Conflicts of Interest}

None declared.

\section{Multimedia Appendix 1}

Search strategies for included studies.

[DOCX File , 23 KB-Multimedia Appendix 1]

\section{Multimedia Appendix 2}

Characteristics of included studies. 
[DOCX File, 37 KB-Multimedia Appendix 2]

\section{References}

1. Cardiovascular diseases. World Health Organization. URL: https://www.who.int/cardiovascular_diseases/en/ [accessed 2019-02-07]

2. Disease expenditure in Australia. Australian Institute of Health and Welfare. 2019 Jun 13. URL: https://www.aihw.gov.au/ reports/health-welfare-expenditure/disease-expenditure-australia/contents/summary [accessed 2019-02-07]

3. Bloom DE, Cafiero ET, Jané-Llopis E, Abrahams-Gessel S, Bloom LR, Fathima S, et al. The Global Economic Burden of Noncommunicable Diseases. Geneva, Switzerland: World Economic Forum; 2011. URL: http://www3.weforum.org/docs/ WEF_Harvard_HE_GlobalEconomicBurdenNonCommunicableDiseases_2011.pdf [accessed 2020-11-12]

4. Benjamin E, Muntner P, Alonso A, Bittencourt MS, Callaway CW, Carson AP, American Heart Association Council on Epidemiology and Prevention Statistics Committee and Stroke Statistics Subcommittee. Heart Disease and Stroke Statistics-2019 Update: A report from the American Heart Association. Circulation 2019 Mar 05;139(10):e56-e528. [doi: 10.1161/CIR.0000000000000659] [Medline: 30700139]

5. Coronary heart disease. Australian Institute of Health and Welfare. URL: https://www.aihw.gov.au/reports/australias-health/ coronary-heart-disease [accessed 2019-02-07]

6. GBD 2017 DALYsHALE Collaborators. Global, regional, and national disability-adjusted life-years (DALYs) for 359 diseases and injuries and healthy life expectancy (HALE) for 195 countries and territories, 1990-2017: A systematic analysis for the Global Burden of Disease Study 2017. Lancet 2018 Nov 10;392(10159):1859-1922 [FREE Full text] [doi: 10.1016/S0140-6736(18)32335-3] [Medline: $\underline{\text { 30415748] }}$

7. Balady GJ, Williams MA, Ades PA, Bittner V, Comoss P, Foody JM, et al. Core components of cardiac rehabilitation/secondary prevention programs: 2007 update. Circulation 2007 May 22;115(20):2675-2682. [doi: 10.1161/circulationaha.106.180945]

8. Cowie A, Buckley J, Doherty P, Furze G, Hayward J, Hinton S, British Association for Cardiovascular PreventionRehabilitation (BACPR). Standards and core components for cardiovascular disease prevention and rehabilitation. Heart 2019 Apr;105(7):510-515 [FREE Full text] [doi: 10.1136/heartjnl-2018-314206] [Medline: 30700518]

9. Writing Group Members, Mozaffarian D, Benjamin EJ, Go AS, Arnett DK, Blaha MJ, American Heart Association Statistics Committee, Stroke Statistics Subcommittee. Heart Disease and Stroke Statistics-2016 Update: A report from the American Heart Association. Circulation 2016 Jan 26;133(4):e38-e360. [doi: 10.1161/CIR.00000000000000350] [Medline: 26673558]

10. Piepoli MF, Corrà U, Adamopoulos S, Benzer W, Bjarnason-Wehrens B, Cupples M, et al. Secondary prevention in the clinical management of patients with cardiovascular diseases. Core components, standards and outcome measures for referral and delivery: A Policy Statement from the Cardiac Rehabilitation Section of the European Association for Cardiovascular Prevention \& Rehabilitation. Endorsed by the Committee for Practice Guidelines of the European Society of Cardiology. Eur J Prev Cardiol 2014 Jun;21(6):664-681. [doi: 10.1177/2047487312449597] [Medline: 22718797]

11. Woodruffe S, Neubeck L, Clark RA, Gray K, Ferry C, Finan J, et al. Australian Cardiovascular Health and Rehabilitation Association (ACRA) core components of cardiovascular disease secondary prevention and cardiac rehabilitation 2014. Heart Lung Circ 2015 May;24(5):430-441. [doi: 10.1016/j.hlc.2014.12.008] [Medline: 25637253]

12. Taylor RS, Brown A, Ebrahim S, Jolliffe J, Noorani H, Rees K, et al. Exercise-based rehabilitation for patients with coronary heart disease: Systematic review and meta-analysis of randomized controlled trials. Am J Med 2004 May 15;116(10):682-692. [doi: 10.1016/j.amjmed.2004.01.009] [Medline: 15121495]

13. Wenger N, Froelicher E, Smith L, Ades P, Berra K, Blumenthal J, et al. Cardiac rehabilitation as secondary prevention. Agency for Health Care Policy and Research and National Heart, Lung, and Blood Institute. Clin Pract Guidel Quick Ref Guide Clin 1995 Oct(17):1-23. [Medline: 8595435$]$

14. Anderson L, Taylor R. Cardiac rehabilitation for people with heart disease: An overview of Cochrane systematic reviews. Int J Cardiol 2014 Dec 15;177(2):348-361. [doi: 10.1016/j.ijcard.2014.10.011] [Medline: 25456575]

15. Shields GE, Wells A, Doherty P, Heagerty A, Buck D, Davies LM. Cost-effectiveness of cardiac rehabilitation: A systematic review. Heart 2018 Sep;104(17):1403-1410 [FREE Full text] [doi: 10.1136/heartjnl-2017-312809] [Medline: 29654096]

16. Wong WP, Feng J, Pwee KH, Lim J. A systematic review of economic evaluations of cardiac rehabilitation. BMC Health Serv Res 2012 Aug 08;12:243 [FREE Full text] [doi: 10.1186/1472-6963-12-243] [Medline: 22873828]

17. De Gruyter E, Ford G, Stavreski B. Economic and social impact of increasing uptake of cardiac rehabilitation services--A cost benefit analysis. Heart Lung Circ 2016 Feb;25(2):175-183. [doi: 10.1016/j.hlc.2015.08.007] [Medline: 26442971]

18. Anderson L, Oldridge N, Thompson D, Zwisler A, Rees K, Martin N, et al. Exercise-based cardiac rehabilitation for coronary heart disease: Cochrane systematic review and meta-analysis. J Am Coll Cardiol 2016 Jan 05;67(1):1-12 [FREE Full text] [doi: 10.1016/j.jacc.2015.10.044] [Medline: 26764059]

19. Kotseva K, Wood D, De Bacquer D, EUROASPIRE Investigators. Determinants of participation and risk factor control according to attendance in cardiac rehabilitation programmes in coronary patients in Europe: EUROASPIRE IV survey. Eur J Prev Cardiol 2018 Aug;25(12):1242-1251. [doi: 10.1177/2047487318781359] [Medline: 29873511]

20. Scott IA, Lindsay KA, Harden HE. Utilisation of outpatient cardiac rehabilitation in Queensland. Med J Aust 2003 Oct 06;179(7):341-345. [doi: 10.5694/j.1326-5377.2003.tb05588.x] 
21. Squires RW. Are cardiac rehabilitation programs underutilized by patients with coronary heart disease? Nat Clin Pract Cardiovasc Med 2008 Apr;5(4):192-193. [doi: 10.1038/ncpcardio1128] [Medline: 18268514]

22. Clark AM, King-Shier KM, Thompson DR, Spaling MA, Duncan AS, Stone JA, et al. A qualitative systematic review of influences on attendance at cardiac rehabilitation programs after referral. Am Heart J 2012 Dec;164(6):835-845.e2. [doi: 10.1016/j.ahj.2012.08.020] [Medline: 23194483]

23. Dunlay SM, Witt BJ, Allison TG, Hayes SN, Weston SA, Koepsell E, et al. Barriers to participation in cardiac rehabilitation. Am Heart J 2009 Nov;158(5):852-859 [FREE Full text] [doi: 10.1016/j.ahj.2009.08.010] [Medline: 19853708]

24. Rose M, Timmons SM, Amerson R, Reimels E, Pruitt RH. Facilitators and barriers in cardiac rehabilitation participation: An integrative review. J Nurse Pract 2011 May;7(5):399-408. [doi: 10.1016/j.nurpra.2011.02.003]

25. Ruano-Ravina A, Pena-Gil C, Abu-Assi E, Raposeiras S, van 't Hof A, Meindersma E, et al. Participation and adherence to cardiac rehabilitation programs. A systematic review. Int J Cardiol 2016 Nov 15;223:436-443. [doi:

10.1016/j.ijcard.2016.08.120] [Medline: 27557484]

26. Neubeck L, Freedman SB, Clark AM, Briffa T, Bauman A, Redfern J. Participating in cardiac rehabilitation: A systematic review and meta-synthesis of qualitative data. Eur J Prev Cardiol 2012 Jun;19(3):494-503. [doi: 10.1177/1741826711409326] [Medline: 22779092]

27. Ades P, Waldmann M, McCann W, Weaver S. Predictors of cardiac rehabilitation participation in older coronary patients. Arch Intern Med 1992 May;152(5):1033-1035. [Medline: 1580707]

28. Ferguson E. Cardiac rehabilitation: An effective and comprehensive but underutilized program to reduce cardiovascular risk in patients with CVD. US Cardiol Rev 2006;2:14e6. [doi: 10.15420/usc.2006.3.2.14]

29. Dalal H, Evans P. Achieving national service framework standards for cardiac rehabilitation and secondary prevention. BMJ 2003 Mar 01;326(7387):481-484 [FREE Full text] [doi: 10.1136/bmj.326.7387.481] [Medline: $\underline{12609946]}$

30. Dalal HM, Zawada A, Jolly K, Moxham T, Taylor RS. Home based versus centre based cardiac rehabilitation: Cochrane systematic review and meta-analysis. BMJ 2010 Jan 19;340:b5631 [FREE Full text] [doi: 10.1136/bmj.b5631] [Medline: 20085991]

31. Jackson AC, Higgins RO, Murphy BM, Rogerson M, Le Grande MR. Cardiac rehabilitation in Australia: A brief survey of program characteristics. Heart Lung Circ 2018 Dec;27(12):1415-1420. [doi: 10.1016/j.hlc.2017.08.024] [Medline: 29100840]

32. Parmanto B, Saptono A. Telerehabilitation: State-of-the-Art from an Informatics Perspective. Int J Telerehabil 2009 Sep;1(1):73-84 [FREE Full text] [doi: 10.5195/ijt.2009.6015] [Medline: 25945164]

33. Clark RA, Conway A, Poulsen V, Keech W, Tirimacco R, Tideman P. Alternative models of cardiac rehabilitation: A systematic review. Eur J Prev Cardiol 2015 Jan;22(1):35-74. [doi: 10.1177/2047487313501093] [Medline: 23943649]

34. Frederix I, Vanhees L, Dendale P, Goetschalckx K. A review of telerehabilitation for cardiac patients. J Telemed Telecare 2014 Dec 04;21(1):45-53. [doi: 10.1177/1357633x14562732]

35. Huang K, Liu W, He D, Huang B, Xiao D, Peng Y, et al. Telehealth interventions versus center-based cardiac rehabilitation of coronary artery disease: A systematic review and meta-analysis. Eur J Prev Cardiol 2015 Aug;22(8):959-971. [doi: 10.1177/2047487314561168] [Medline: 25488550]

36. Jin K, Khonsari S, Gallagher R, Gallagher P, Clark AM, Freedman B, et al. Telehealth interventions for the secondary prevention of coronary heart disease: A systematic review and meta-analysis. Eur J Cardiovasc Nurs 2019 Apr;18(4):260-271. [doi: $10.1177 / 1474515119826510]$ [Medline: $\underline{30667278}$ ]

37. Rawstorn JC, Gant N, Direito A, Beckmann C, Maddison R. Telehealth exercise-based cardiac rehabilitation: A systematic review and meta-analysis. Heart 2016 Aug 01;102(15):1183-1192. [doi: 10.1136/heartjnl-2015-308966] [Medline: 26936337]

38. Neubeck L, Redfern JU, Fernandez R, Briffa T, Bauman A, Freedman SB. Telehealth interventions for the secondary prevention of coronary heart disease: A systematic review. Eur J Cardiovasc Prev Rehabil 2009 Jun;16(3):281-289. [doi: 10.1097/hjr.0b013e32832a4e7a]

39. Mackay MM. Australian Mobile Phone Lifestyle Index, 9th edition. Sydney, Australia: AIMIA; 2013 Oct. URL: https:/ /www.sponsor-ed.com.au/app/webroot/uploaded_files/media/Ampli\%202013\%20Report_Final_October\%2024.pdf [accessed 2020-11-09]

40. Neubeck L, Lowres N, Benjamin EJ, Freedman SB, Coorey G, Redfern J. The mobile revolution--Using smartphone apps to prevent cardiovascular disease. Nat Rev Cardiol 2015 Jun;12(6):350-360. [doi: 10.1038/nrcardio.2015.34] [Medline: 25801714]

41. Chow CK, Redfern J, Hillis GS, Thakkar J, Santo K, Hackett ML, et al. Effect of lifestyle-focused text messaging on risk factor modification in patients with coronary heart disease: A randomized clinical trial. JAMA 2015;314(12):1255-1263. [doi: 10.1001/jama.2015.10945] [Medline: 26393848]

42. Pfaeffli Dale L, Whittaker R, Jiang Y, Stewart R, Rolleston A, Maddison R. Text message and internet support for coronary heart disease self-management: Results from the Text4Heart randomized controlled trial. J Med Internet Res 2015 Oct 21;17(10):e237 [FREE Full text] [doi: 10.2196/jmir.4944] [Medline: 26490012]

43. Maddison R, Pfaeffli L, Whittaker R, Stewart R, Kerr A, Jiang Y, et al. A mobile phone intervention increases physical activity in people with cardiovascular disease: Results from the HEART randomized controlled trial. Eur J Prev Cardiol 2015 Jun;22(6):701-709. [doi: 10.1177/2047487314535076] [Medline: 24817694] 
44. Varnfield M, Karunanithi M, Lee C, Honeyman E, Arnold D, Ding H, et al. Smartphone-based home care model improved use of cardiac rehabilitation in postmyocardial infarction patients: Results from a randomised controlled trial. Heart 2014 Nov;100(22):1770-1779 [FREE Full text] [doi: 10.1136/heartjnl-2014-305783] [Medline: 24973083]

45. Maddison R, Rawstorn JC, Stewart RAH, Benatar J, Whittaker R, Rolleston A, et al. Effects and costs of real-time cardiac telerehabilitation: Randomised controlled non-inferiority trial. Heart 2019 Jan;105(2):122-129 [FREE Full text] [doi: 10.1136/heartjnl-2018-313189] [Medline: $\underline{30150328}$ ]

46. Milat AJ, Bauman AE, Redman S, Curac N. Public health research outputs from efficacy to dissemination: A bibliometric analysis. BMC Public Health 2011 Dec 15;11:934 [FREE Full text] [doi: 10.1186/1471-2458-11-934] [Medline: 22168312]

47. Wiltsey Stirman S, Kimberly J, Cook N, Calloway A, Castro F, Charns M. The sustainability of new programs and innovations: A review of the empirical literature and recommendations for future research. Implement Sci 2012 Mar 14;7:17 [FREE Full text] [doi: 10.1186/1748-5908-7-17] [Medline: 22417162]

48. Wolfenden L, Chai LK, Jones J, McFadyen T, Hodder R, Kingsland M, et al. What happens once a program has been implemented? A call for research investigating strategies to enhance public health program sustainability. Aust N Z J Public Health 2019 Feb;43(1):3-4. [doi: 10.1111/1753-6405.12867] [Medline: 30690829]

49. Tabak RG, Khoong EC, Chambers DA, Brownson RC. Bridging research and practice: Models for dissemination and implementation research. Am J Prev Med 2012 Sep;43(3):337-350 [FREE Full text] [doi: 10.1016/j.amepre.2012.05.024] [Medline: 22898128]

50. Koorts H, Eakin E, Estabrooks P, Timperio A, Salmon J, Bauman A. Implementation and scale up of population physical activity interventions for clinical and community settings: The PRACTIS guide. Int J Behav Nutr Phys Act 2018 Jun 08;15(1):51 [FREE Full text] [doi: 10.1186/s12966-018-0678-0] [Medline: 29884236]

51. Reis RS, Salvo D, Ogilvie D, Lambert EV, Goenka S, Brownson RC. Scaling up physical activity interventions worldwide: Stepping up to larger and smarter approaches to get people moving. Lancet 2016 Sep;388(10051):1337-1348. [doi: 10.1016/s0140-6736(16)30728-0]

52. PROSPERO: International prospective register of systematic reviews. National Institute for Health Research. URL: https:/ /www.crd.york.ac.uk/prospero/ [accessed 2019-02-07]

53. Liberati A, Altman DG, Tetzlaff J, Mulrow C, Gøtzsche PC, Ioannidis JPA, et al. The PRISMA statement for reporting systematic reviews and meta-analyses of studies that evaluate health care interventions: Explanation and elaboration. PLoS Med 2009 Jul 21;6(7):e1000100 [FREE Full text] [doi: 10.1371/journal.pmed.1000100] [Medline: 19621070]

54. Proctor E, Silmere H, Raghavan R, Hovmand P, Aarons G, Bunger A, et al. Outcomes for implementation research: Conceptual distinctions, measurement challenges, and research agenda. Adm Policy Ment Health 2011 Mar;38(2):65-76 [FREE Full text] [doi: 10.1007/s10488-010-0319-7] [Medline: 20957426]

55. Damschroder LJ, Aron DC, Keith RE, Kirsh SR, Alexander JA, Lowery JC. Fostering implementation of health services research findings into practice: A consolidated framework for advancing implementation science. Implement Sci 2009 Aug 07;4:50 [FREE Full text] [doi: 10.1186/1748-5908-4-50] [Medline: 19664226]

56. Greenhalgh T, Wherton J, Papoutsi C, Lynch J, Hughes G, A'Court C, et al. Beyond adoption: A new framework for theorizing and evaluating nonadoption, abandonment, and challenges to the scale-up, spread, and sustainability of health and care technologies. J Med Internet Res 2017 Nov 01;19(11):e367 [FREE Full text] [doi: 10.2196/jmir.8775] [Medline: 29092808]

57. Rayyan QCRI: Qatar Computing Research Institute. URL: https://rayyan.qcri.org/welcome

58. Higgins JPT, Green S, editors. Cochrane Handbook for Systematic Reviews of Interventions. Hoboken, NJ: John Wiley \& Sons; 2008.

59. Moola S, Munn Z, Tufanaru C, Aromataris E, Sears K, Sfetcu R. Systematic reviews of etiology and risk. In: JBI Manual for Evidence Synthesis. Adelaide, Australia: JBI; 2020:255-257.

60. Kraal JJ, Van den Akker-Van Marle ME, Abu-Hanna A, Stut W, Peek N, Kemps HM. Clinical and cost-effectiveness of home-based cardiac rehabilitation compared to conventional, centre-based cardiac rehabilitation: Results of the FIT@ Home study. Eur J Prev Cardiol 2017 Aug;24(12):1260-1273 [FREE Full text] [doi: 10.1177/2047487317710803] [Medline: 28534417]

61. Lear S, Singer J, Banner-Lukaris D, Horvat D, Park J, Bates J, et al. Improving access to cardiac rehabilitation using the internet: A randomized trial. Stud Health Technol Inform 2015;209:58-66. [Medline: 25980706]

62. Park LG, Howie-Esquivel J, Chung ML, Dracup K. A text messaging intervention to promote medication adherence for patients with coronary heart disease: A randomized controlled trial. Patient Educ Couns 2014 Feb;94(2):261-268. [doi: 10.1016/j.pec.2013.10.027] [Medline: 24321403]

63. Piotrowicz E, Korzeniowska-Kubacka I, Chrapowicka A, Wolszakiewicz J, Dobraszkiewicz-Wasilewska B, Batogowski M, et al. Feasibility of home-based cardiac telerehabilitation: Results of TeleInterMed study. Cardiol J 2014 Oct 29;21(5):539-546. [doi: 10.5603/cj.a2014.0005]

64. Salvi D, Ottaviano M, Muuraiskangas S, Martínez-Romero A, Vera-Muñoz C, Triantafyllidis A, et al. An m-Health system for education and motivation in cardiac rehabilitation: The experience of HeartCycle guided exercise. J Telemed Telecare 2017 Mar 28;24(4):303-316. [doi: 10.1177/1357633x17697501] 
65. Redfern J, Santo K, Coorey G, Thakkar J, Hackett M, Thiagalingam A, et al. Factors influencing engagement, perceived usefulness and behavioral mechanisms associated with a text message support program. PLoS One 2016;11(10):e0163929 [FREE Full text] [doi: 10.1371/journal.pone.0163929] [Medline: 27741244]

66. Kraal JJ, Peek N, van den Akker-Van Marle ME, Kemps HM. Effects and costs of home-based training with telemonitoring guidance in low to moderate risk patients entering cardiac rehabilitation: The FIT@Home study. BMC Cardiovasc Disord 2013 Oct 08;13:82 [FREE Full text] [doi: 10.1186/1471-2261-13-82] [Medline: 24103384]

67. Banner D, Lear S, Kandola D, Singer J, Horvat D, Bates J, et al. The experiences of patients undertaking a 'virtual' cardiac rehabilitation program. Stud Health Technol Inform 2015;209:9-14. [Medline: 25980699]

68. Pfaeffli Dale L, Whittaker R, Dixon R, Stewart R, Jiang Y, Carter K, et al. Acceptability of a mobile health exercise-based cardiac rehabilitation intervention. J Cardiopulm Rehabil Prev 2015;35(5):312-319. [doi: 10.1097/hcr.0000000000000125]

69. Rawstorn JC, Gant N, Rolleston A, Whittaker R, Stewart R, Benatar J, et al. End users want alternative intervention delivery models: Usability and acceptability of the REMOTE-CR exercise-based cardiac telerehabilitation program. Arch Phys Med Rehabil 2018 Nov;99(11):2373-2377. [doi: 10.1016/j.apmr.2018.06.027] [Medline: 30076800]

70. Szalewska D, Zieliński P, Tomaszewski J, Kusiak-Kaczmarek M, Łepska L, Gierat-Haponiuk K, et al. Effects of outpatient followed by home-based telemonitored cardiac rehabilitation in patients with coronary artery disease. Kardiol Pol 2015;73(11):1101-1107. [doi: 10.5603/KP.a2015.0095] [Medline: 25987401]

71. Skobel E, Knackstedt C, Martinez-Romero A, Salvi D, Vera-Munoz C, Napp A, et al. Internet-based training of coronary artery patients: The Heart Cycle Trial. Heart Vessels 2017 Apr;32(4):408-418. [doi: 10.1007/s00380-016-0897-8] [Medline: 27730298]

72. Wandersman A, Duffy J, Flaspohler P, Noonan R, Lubell K, Stillman L, et al. Bridging the gap between prevention research and practice: The interactive systems framework for dissemination and implementation. Am J Community Psychol 2008 Jun;41(3-4):171-181. [doi: 10.1007/s10464-008-9174-z] [Medline: 18302018]

73. Dalal H, Doherty P, Taylor R. Cardiac rehabilitation. BMJ 2015 Sep 29;351:h5000 [FREE Full text] [doi: 10.1136/bmj.h5000] [Medline: 26419744]

74. Chaudoir SR, Dugan AG, Barr CHI. Measuring factors affecting implementation of health innovations: A systematic review of structural, organizational, provider, patient, and innovation level measures. Implement Sci 2013 Feb 17;8:22 [FREE Full text] [doi: 10.1186/1748-5908-8-22] [Medline: 23414420]

75. Karsh B. Beyond usability: Designing effective technology implementation systems to promote patient safety. Qual Saf Health Care 2004 Oct 01;13(5):388-394. [doi: 10.1136/qshc.2004.010322]

76. Brownson R, Colditz G, Proctor E, editors. Dissemination and Implementation Research in Health: Translating Science to Practice. 2nd edition. New York, NY: Oxford University Press; 2018.

77. Greenhalgh T, A'Court C, Shaw S. Understanding heart failure; explaining telehealth - A hermeneutic systematic review. BMC Cardiovasc Disord 2017 Jun 14;17(1):156 [FREE Full text] [doi: 10.1186/s12872-017-0594-2] [Medline: 28615004]

78. Dearing JW. Evolution of diffusion and dissemination theory. J Public Health Manag Pract 2008;14(2):99-108. [doi: 10.1097/01.phh.0000311886.98627.b7]

79. Grace SL, Turk-Adawi KI, Contractor A, Atrey A, Campbell N, Derman W, et al. Cardiac rehabilitation delivery model for low-resource settings. Heart 2016 Sep 15;102(18):1449-1455 [FREE Full text] [doi: 10.1136/heartjnl-2015-309209] [Medline: 27181874]

80. Korenfeld Y, Mendoza-Bastidas C, Saavedra L, Montero-Gómez A, Perez-Terzic C, Thomas RJ, et al. Current status of cardiac rehabilitation in Latin America and the Caribbean. Am Heart J 2009 Sep;158(3):480-487. [doi: 10.1016/j.ahj.2009.06.020] [Medline: 19699874]

81. Oldridge NB, Pakosh MT, Thomas RJ. Cardiac rehabilitation in low- and middle-income countries: A review on cost and cost-effectiveness. Int Health 2016 Mar;8(2):77-82. [doi: 10.1093/inthealth/ihv047] [Medline: 26208507]
Abbreviations
CHD: coronary heart disease
CR: cardiac rehabilitation
CVD: cardiovascular disease
ICT: information and communication technology
MI: myocardial infarction
PRISMA: Preferred Reporting Items for Systematic Reviews and Meta-Analyses
PROSPERO: International Prospective Register of Systematic Reviews
RCT: randomized controlled trial 
Edited by C Dias; submitted 23.01.20; peer-reviewed by SY Chen, S Olsen, G Chappell; comments to author 17.03.20; revised version received 02.07.20; accepted 15.07.20; published 27.11 .20

Please cite as:

Subedi N, Rawstorn JC, Gao L, Koorts H, Maddison R

Implementation of Telerehabilitation Interventions for the Self-Management of Cardiovascular Disease: Systematic Review JMIR Mhealth Uhealth 2020;8(11):e17957

URL: http://mhealth.jmir.org/2020/11/e17957/

doi: $\underline{10.2196 / 17957}$

PMID: $\underline{3245286}$

CNarayan Subedi, Jonathan C Rawstorn, Lan Gao, Harriet Koorts, Ralph Maddison. Originally published in JMIR mHealth and uHealth (http://mhealth.jmir.org), 27.11.2020. This is an open-access article distributed under the terms of the Creative Commons Attribution License (https://creativecommons.org/licenses/by/4.0/), which permits unrestricted use, distribution, and reproduction in any medium, provided the original work, first published in JMIR mHealth and uHealth, is properly cited. The complete bibliographic information, a link to the original publication on http://mhealth.jmir.org/, as well as this copyright and license information must be included. 